\title{
Correction to: Digitalization of Business Logistics Activities and Future Directions
}

Correction to:

The original version of Chapter 10 was inadvertently published with the incorrect 10 authors affiliation.

For authors Ebru Beyza Bayarçelik and Hande Begüm Bumin Doyduk the 12 corrected affiliation is provided below:

Department of International Trade and Logistics Management, Faculty of 15 Business and Management Science, Maltepe University, Maltepe, Istanbul, Turkey 16 e-mail: ebrubeyzabayarcelik@maltepe.edu.tr

Hande Begüm Bumin Doyduk

Hande Begüm Bumin Doyduk (Corresponding author), Department of Interna- 19 tional Trade, School of Business, Altınbaş University, Esentepe, Istanbul, Turkey 20 e-mail: hande.doyduk@altinbas.edu.tr 